\title{
Influência do conteúdo de umidade de colheita e temperatura de secagem na qualidade do feijão
}

Lêda R. A. Faroni ${ }^{1}$, Izabel C. Cordeiro ${ }^{1}$, Ernandes R. de Alencar ${ }^{1}$, Adriano F. Rozado ${ }^{1}$ \& Wederson M. Alves ${ }^{1}$

\section{RESUMO}

Apesar dos avanços, a produção brasileira de feijão sofre perdas consideráveis, até chegar ao consumidor, razão por que se objetivou, com este trabalho, avaliar a qualidade do feijão colhido com diferentes conteúdos de água e secados em diferentes temperaturas do ar, em um secador de camada delgada. Após a limpeza e secagem, os grãos foram expurgados e, em seguida, acondicionados em recipientes metálicos e mantidos em condições de laboratório, durante o período de 90 dias. A avaliação da qualidade foi realizada pela classificação do feijão, pela condutividade elétrica e pela coloração dos grãos, em intervalos de 30 dias. Concluiu-se, daí, que os grãos colhidos com conteúdo de água de 18,7\% apresentaram a melhor classificação por tipo, enquanto os grãos colhidos, com 20,6 e 18,7\%, indicavam qualidade fisiológica superior à dos grãos colhidos secos. $\mathrm{O}$ aumento da temperatura do ar de secagem não teve efeito sobre a classificação por tipo nem sobre a coloração, mas reduziu a qualidade fisiológica dos grãos. Em relação ao armazenamento dos grãos, concluiu-se que a classificação por tipo se manteve a mesma, porém sua qualidade fisiológica foi reduzida e os grãos tenderam ao escurecimento.

Palavras-chave: armazenamento, coloração, classificação

\section{Influence of the harvest moisture content and of the drying temperature upon the bean quality}

\begin{abstract}
Considerable losses occur in the post-harvest process of the Brazilian bean production. The objective of this work was to evaluate the bean quality harvested at different moisture contents and dried using different air temperatures in a thin layer dryer. After cleaning and drying, the grains were fumigated and, soon after, conditioned in metallic recipients and kept under laboratory conditions during a period of 90 days. The evaluation of the quality was accomplished by classifying the beans and measuring the electrical conductivity, the color, the breakage susceptibility and the hardening degree of the grains, in intervals of 30 days. It was concluded that grains harvested with moisture content of $18.7 \%$ presented the best classification grade and physiological quality of the grains harvested at 20.6 and $18.7 \%$ was superior in comparison to grains harvested at $11.7 \%$. The increase of the drying air temperatures did not have effect either upon the type or upon the color classification; however, it reduced the physiological quality of the grains. Regarding the grains storage, it was concluded that the classification grade remained the same; however, the physiological quality of the grains was reduced, and the grains tended to become dark.
\end{abstract}

Key words: storage, coloration, classification 


\section{INTRODUÇÃO}

Nos últimos anos, o Brasil vem produzindo grandes safras, o que o tem colocado entre os maiores produtores de grão. A safra brasileira de 02.03 foi de 122,4 milhões de toneladas e se estima que a safra de 03.04 será de 129,7 milhões de toneladas de grão (CONAB, 2003). Os principais produtos da agricultura brasileira são a soja, o milho, o arroz e o feijão que, juntos, representam mais de $92 \%$ do total produzido na safra de 02.03 ; a produção de feijão, de 3,2 milhões de toneladas, representou $2,6 \%$ do total de grãos produzidos.

Apesar dos avanços, a produção interna de feijão sofre perdas consideráveis, até chegar ao consumidor. As perdas pós-colheita constituem um dos fatores mais significativos no fornecimento mundial de alimentos, representando 5-10\% da produção mundial de grãos e oleaginosa (Richard \& Molard, citados por Tipples, 1995).

A maior parte dos grãos, depois de colhidos, possui características inadequadas ao armazenamento, em razão principalmente do alto conteúdo de água na época da colheita e da presença de impurezas e matérias estranhas necessitando, portanto, de tratamentos pós-colheita para que, durante o armazenamento, a qualidade e a quantidade dos grãos sejam preservadas (Bailey, 1992).

Dentre as operações pós-colheita, o processo de secagem tem papel significativo nas perdas de grãos, uma vez que seu manejo incorreto ocasiona deterioração dos grãos, ao longo do armazenamento. Radajewski et al. (1992), estudando a taxa de secagem em grãos de feijão "Navy" com conteúdo de água em torno de $25 \%$ base úmida (b.u.), com temperatura do ar de secagem variando de 32 a $62{ }^{\circ} \mathrm{C}$, concluíram que o nível de dano está diretamente relacionado com a umidade relativa do ar de secagem. Segundo eles, a temperatura do ar de secagem e, conseqüentemente, a taxa de secagem, exercem pouco efeito sobre a qualidade final do produto. Os autores salientam, ainda, que a variedade do feijão pode ter importante correlação com o tipo de dano causado aos grãos pela secagem, sendo necessários mais estudos sobre este assunto.

Considerando que o processo de secagem utilizado pode afetar a capacidade de armazenamento dos grãos, Afonso Júnior (1997), estudando os efeitos do processo de secagem na qualidade de sementes de feijão da variedade "Ouro Negro 1992", verificou que a temperatura do ar de secagem e os conteúdos de água inicial e final dos grãos, afetam a germinação e o vigor das sementes. Este efeito foi menos acentuado em grãos colhidos com $17,1 \%$ b.u. de conteúdo de água inicial.

As características ideais para o feijão, são: tamanho do grão, cor, aparência, propriedades e tempo de cozimento, aspectos de hidratação, conteúdo protéico etc. (Durigan et al., 1978; Chiaradia \& Gomes, 1997). A perda de qualidade dos grãos de feijão durante o armazenamento é caracterizada pelo aumento do tempo de cozimento, aumento do grau de dureza do tegumento e alterações da cor (escurecimento) e do sabor.

A alteração na coloração dos produtos agrícolas está fre- qüentemente associada às características de qualidade desejada ou não, pelos processadores e consumidores. Desta forma, a alteração na coloração de produtos agrícolas é um atributo de qualidade de fácil identificação. As alterações na coloração de grãos de feijão podem ser causadas pela oxidação de leucoatocianinas catalisadas pelo ar e pela luz, apesar do escurecimento não-enzimático também ser uma possibilidade (Stanley citado por Chiaradia \& Gomes, 1997).

Em função do exposto objetivou-se, com este trabalho, avaliar a qualidade dos grãos de feijão ao longo do armazenamento, colhidos com diferentes conteúdos de água e secados em diferentes temperaturas do ar de secagem, ao longo do armazenamento.

\section{MATERIAL E MÉTODOS}

Este trabalho foi realizado no Setor de Pré-Processamento de Produtos Agrícolas do Departamento de Engenharia Agrícola e no Laboratório de Propriedades Físicas do CENTREINAR, ambos localizados na Universidade Federal de Viçosa, Viçosa, MG.

Utilizaram-se grãos de feijão (Phaseolus vulgaris L.) da variedade "Carioca 1030", colhidos no Campo Experimental do Centro Nacional de Pesquisa de Milho e Sorgo CNPMS/EMBRAPA, na cidade de Sete Lagoas, MG.

A colheita foi feita em períodos distintos e dividida em três etapas, em que na primeira se colheu uma parcela do produto quando o conteúdo de água dos grãos estava em torno de $21 \%$ b.u.; a segunda colheita foi realizada quando os grãos apresentavam conteúdo de água de aproximadamente $18 \%$ b.u. e o restante foi colhido quando o conteúdo de água dos grãos era de aproximadamente $12 \%$ b.u.

Os grãos foram arrancados manualmente e recolhidos, utilizando-se uma recolhedora Penha Modelo "CLC 500", com um cilindro trilhador de $0,60 \mathrm{~m}$ de diâmetro e 2,6 m de comprimento. A recolhedora foi acionada por um trator em velocidade de $1 \mathrm{~km} \mathrm{~h}^{-1}$ que, durante a colheita, operou com a rotação de $540 \mathrm{rpm}$ no eixo do cilindro trilhador, $1.388 \mathrm{rpm}$ no eixo do ventilador e $320 \mathrm{rpm}$ no excêntrico que movimenta as peneiras.

A secagem do feijão com conteúdos de água de 21 e $18 \%$ b.u. foi realizada em um secador experimental de camada delgada, com controle de temperatura (por meio de três resistências elétricas) e velocidade do ar de secagem (através da abertura e do fechamento do diafragma acoplado, na entrada do ventilador). Os testes só foram iniciados quando a velocidade do ar de secagem atingia $0,7 \mathrm{~m} \mathrm{~s}^{-1}$, medida por meio de um anemômetro digital de lâminas rotativas, e quando a temperatura do ar era de $30,40,50$ e $60^{\circ} \mathrm{C}$, e se mantinha constante; a temperatura foi medida com um termômetro de mercúrio de $1{ }^{\circ} \mathrm{C}$ de precisão, localizado imediatamente abaixo da bandeja, em que se encontravam os grãos de feijão.

A massa de grãos, que formava uma camada de aproximadamente $2,5 \mathrm{~cm}$ de altura, era acomodada em uma bandeja de $53 \mathrm{~cm}$ de diâmetro com fundo telado.

Durante o processo de secagem pesou-se a bandeja com os grãos, periodicamente, até que os grãos atingissem o 
conteúdo de água médio de $12 \%$ b.u. Conhecendo-se o peso inicial dos grãos, o conteúdo de água e final desejados, calculava-se o peso final dos grãos secados, que correspondia ao conteúdo de água desejado (12\% b.u.).

O feijão que não foi submetido ao processo de secagem pelo fato de ter sido colhido com conteúdo de água de aproximadamente $12 \%$, foi mantido em uma câmara climática com temperatura de $10^{\circ} \mathrm{C}$ e $65 \%$ de UR, até o início do período de armazenamento, por mais ou menos 15 dias. De acordo com diversos autores, nestas condições a qualidade inicial dos grãos não é afetada.

Finalizada a secagem, amostras de quase $7 \mathrm{~kg}$ de grão de feijão secados em quatro temperaturas do ar de secagem (30, 40,50 e $60^{\circ} \mathrm{C}$ ) e dos grãos colhidos com um conteúdo de água de aproximadamente $12 \%$ b.u., foram acondicionadas em recipientes metálicos de aproximadamente $0,018 \mathrm{~m}^{-3}$, para o armazenamento; em seguida, os recipientes foram desinfestados por meio de uma fumigação com fosfeto de alumínio, empregando-se uma dosagem de $1,0 \mathrm{~g} \mathrm{~m}^{-3}$ do princípio ativo, durante $72 \mathrm{~h}$ de exposição; após o expurgo, os recipientes foram cobertos com uma malha de algodão muito fina, de forma a possibilitar a respiração dos grãos e impedir a reinfestação por insetos provenientes do meio ambiente externo. Esses recipientes foram, então, armazenados em laboratório, durante 90 dias.

Para avaliar a qualidade dos grãos de feijão colhidos com conteúdos de água de 21,18 e $12 \%$ e secados a temperaturas do ar de secagem de $30,40,50$ e $60{ }^{\circ} \mathrm{C}$, durante o armazenamento, coletou-se, no início e a cada 30 dias, uma amostra de $1,5 \mathrm{~kg}$ em cada recipiente metálico, as quais, além de classificadas, foram submetidas às análises de condutividade elétrica e de coloração dos grãos.

\section{Classificação do feijão}

A classificação dos grãos de feijão foi feita pela Delegacia Federal de Agricultura, em Minas Gerais, Ministério da Agricultura, do Abastecimento e da Reforma Agrária (MAARA), em Belo Horizonte, MG, de acordo com as normas de classificação do feijão (Brasil, 1987).

\section{Teste de condutividade elétrica}

Fez-se a condutividade elétrica da solução contendo os grãos de feijão utilizando-se o "Sistema de copo" ou "Condutividade de massa" (Vieira \& Carvalho, 1994). Os testes foram realizados em quatro repetições de 50 grãos para cada tratamento (conteúdo de água da colheita). Os grãos foram pesados em uma balança com precisão de $0,01 \mathrm{~g}$ e colocados em copos plásticos de $200 \mathrm{~mL}$, aos quais foram adicionados $75 \mathrm{~mL}$ de água deionizada; logo após, os copos foram colocados em um germinador, a temperatura de $25{ }^{\circ} \mathrm{C}$ por $24 \mathrm{~h}$; imediatamente depois deste período, os copos foram retirados do germinador para a realização das medições da condutividade elétrica da solução que contém os grãos.

As leituras foram feitas em medidor de condutividade elétrica da marca Digimed, modelo CD-21, com ajuste para compensação da temperatura e eletrodo com constante da célula de $1 \mu \mathrm{S} \mathrm{cm}^{-1}$. Antes de se realizar as leituras, o aparelho foi calibrado com uma solução-padrão de cloreto de só- dio, de condutividade elétrica conhecida, a temperatura de $25^{\circ} \mathrm{C}$.

$\mathrm{O}$ valor de condutividade $\left(\mu \mathrm{S} \mathrm{cm}^{-1}\right)$ fornecido pelo aparelho foi dividido pela massa ( $\mathrm{g}$ ) dos 50 grãos obtendo-se, então, o valor de condutividade elétrica, expresso com base no peso seco da amostra, em $\mu \mathrm{S} \mathrm{cm}^{-1} \mathrm{~g}^{-1}$.

\section{Teste de coloração}

A avaliação das alterações na coloração dos grãos de feijão foi realizada por meio do Sistema de Hunter; o aparelho utilizado foi o Colorímetro Mini Scan ${ }^{\mathrm{TM}}$ XE Plus. As medições das coordenadas de Hunter, $L_{H}, a_{H}$ e $b_{H}$, foram feitas utilizando-se o instrumento HunterLab. Os valores de cor usados neste aparelho são relativos aos valores absolutos de uma perfeita reflexão difusa, medida sobre algumas condições geométricas, recomendadas pela CIE (Commission Internationale d'Eclariage).

Os testes foram realizados em três repetições para cada tratamento, utilizando-se amostras de grãos inteiros e limpos. Os grãos foram limpados com um tecido macio de algodão para que não houvesse qualquer alteração nas leituras, em função de partículas de solo que, por ventura, estivessem aderidas aos grãos, e as amostras foram colocadas no aparelho para a realização das leituras, obtendo-se os valores das coordenadas de Hunter:

- $\mathrm{L}_{\mathrm{H}}$ varia do branco (100) ao preto (0)

- $\mathrm{a}_{\mathrm{H}}$ varia do vermelho $(+\mathrm{a})$ ao verde $(-\mathrm{a})$

- $b_{\mathrm{H}}$ varia do amarelo (+b) ao azul (-b)

Utilizando-se os valores de $\mathrm{L}_{\mathrm{H}}, \mathrm{b}_{\mathrm{H}}$ e $\mathrm{a}_{\mathrm{H}}$, calcularam-se os valores dos índices cromáticos matiz $(\mathrm{H})$ e croma $(\mathrm{C})$ do Sistema de Munsell. O Sistema de Munsell é um espaço tridimensional no se qual situam todas as cores, em função da tonalidade, claridade e saturação (matiz, valor e croma) (Calvo, 1989).

Obtiveram-se os valores dos índices cromáticos por meio da transformação das coordenadas cartesianas em coordenadas cilíndricas:

$$
\begin{gathered}
\mathrm{C}=\sqrt{\left(\mathrm{a}_{\mathrm{H}}{ }^{2}+\mathrm{b}_{\mathrm{H}}{ }^{2}\right)} \\
\mathrm{H}=\arctan \left(\frac{\mathrm{b}_{\mathrm{H}}}{\mathrm{a}_{\mathrm{H}}}\right)
\end{gathered}
$$

\section{Análise estatística dos dados}

Os efeitos do conteúdo de água de colheita na qualidade dos grãos foram avaliados por meio de um teste de médias, teste de Tukey.

Para avaliação dos efeitos das temperaturas do ar de secagem e dos períodos de armazenamento sobre a qualidade dos grãos, optou-se por ajustar modelos estatísticos de predição. Com os modelos, obtiveram-se as superfícies de resposta em função do período de armazenamento, para cada temperatura do ar de secagem e para cada conteúdo de água de colheita.

Os modelos foram ajustados a partir do modelo estatístico linear completo: 


$$
\hat{\mathrm{Y}}_{\mathrm{ij}}=\beta_{0}+\beta_{1} \mathrm{t}+\beta_{2} \mathrm{~T}+\beta_{3} \mathrm{t}^{2}+\beta_{4} \mathrm{~T}^{2}+\beta_{5} \mathrm{t} \cdot \mathrm{T}+e_{i j}
$$

em que:

$\mathrm{Y}_{\mathrm{ij}}$ - estimativa dos parâmetros de qualidade avaliados no tempo $\mathrm{j}$ e nas temperaturas de secagem $\mathrm{i}$, sendo $\mathrm{j}=1$, $2,3,4$ e $\mathrm{i}=1,2,3,4$

$\beta_{0}$ - constante da regressão

$\beta_{\mathrm{k}}-$ coeficiente de regressão, $\mathrm{k}=1,2,3,4,5$

$\mathrm{t}_{\mathrm{j}}$ - efeito do período de armazenamento $\mathrm{j}$, para os níveis de $0,30,60$ e 90 dias

$\mathrm{T}_{\mathrm{i}}$ - efeito das temperaturas de secagem $\mathrm{i}$, para os níveis de $30,40,50$ e $60{ }^{\circ} \mathrm{C}$

$e_{\mathrm{ij}}-$ erro aleatório

A escolha do modelo de predição a partir do modelo completo baseou-se nos coeficientes de determinação.

\section{RESULTADOS E DISCUSSÃO}

\section{Classificação dos grãos}

O resumo dos laudos de classificação dos grãos de feijão colhidos, secados e depois limpos, e dos grãos colhidos com conteúdos de água de 20,6 e 18,7\%, após terem sido submetidos à limpeza e secagem, emitidos pelo MAARA, é apresentado na Tabela 1 . Verifica-se que os grãos colhidos com um conteúdo de água de $11,7 \%$ foram classificados como do tipo 3, mesmo depois de limpos, enquanto os grãos colhidos com $18,7 \%$, independentemente da temperatura do ar de secagem, foram classificados como do tipo 2. Na mesma tabela se observa que os grãos de feijão colhidos um conteúdo de água de $20,6 \%$ e secados em temperaturas do ar de secagem de 30 e $40{ }^{\circ} \mathrm{C}$, foram classificados como do tipo 2, mas se pode verificar que ocorreu aumento dos grãos partidos em relação aos grãos colhidos com conteúdo de água de 18,7\%; já nas temperaturas de 50 e $60^{\circ} \mathrm{C}$, o aumento de grãos partidos ficou mais evidenciado e, conseqüentemente, maior foi o total de grãos avariados, razão pela qual foram classificados como tipo 3 .
Sabendo-se que o processo de secagem pode reduzir, de forma sensível, a qualidade dos grãos (Brooker et al., 1992) e que, no caso do feijão, a porcentagem de grãos partidos pode aumentar significativamente com a redução do seu conteúdo de água, analisou-se o percentual de grãos partidos em função da temperatura do ar de secagem, para os conteúdos de água de 20,6 e $18,7 \%$.

Os resultados da análise de variância para o percentual de grãos partidos, colhidos com conteúdos de água de 20,6 e $18,7 \%$ e secados nas temperaturas do ar de secagem de 30 , 40,50 e $60{ }^{\circ} \mathrm{C}$ indicam, pelo teste $\mathrm{F}$, em nível de $5 \%$ de probabilidade, que houve efeito significativo apenas do conteúdo de água de colheita sobre o percentual de grãos partidos.

A Tabela 2 apresenta os resultados médios do percentual de grãos partidos para os conteúdos de água de colheita de 20,6 e $18,7 \%$. Verifica-se que o percentual de grãos partidos é maior para o conteúdo de água de colheita de $20,6 \%$, independentemente da temperatura do ar de secagem.

Tabela 2. Valores médios do percentual de grãos partidos para os grãos colhidos com 20,6 e 18,7\% de conteúdo de água, após a secagem

\begin{tabular}{cc}
\hline Conteúdo de água (\%) & Percentual de grãos partidos (\%) \\
18,7 & $1,82 \mathrm{~b}$ \\
20,6 & $2,72 \mathrm{a}$ \\
\hline
\end{tabular}

As médias seguidas de uma mesma letra, para cada conteúdo de água de colheita, não diferem significativamente entre si pelo teste $\mathrm{F}$ a $5 \%$ de probabilidade.

Os demais parâmetros de qualidade dos grãos não foram comparados, em razão do processo de secagem ter sido realizado com os grãos em camada estática. Com relação ao período de armazenamento, os grãos mantiveram a mesma classificação por tipo, até o final dos 90 dias.

\section{Condutividade elétrica}

Os valores médios da condutividade elétrica da solução que contém os grãos de feijão colhidos com 20,6 e 18,7\% de conteúdo de água e secados em quatro temperaturas do ar de secagem, foram comparados com o valor médio da condutividade elétrica dos grãos colhidos com $11,7 \%$ de

Tabela 1. Valores médios dos grãos colhidos com diferentes conteúdos de água, limpos e secados em diferentes temperaturas do ar de secagem e dos grãos colhidos, secados e depois limpos, obtidos dos Laudos de Classificação de Feijão, realizados pelo Ministério da Agricultura

\begin{tabular}{|c|c|c|c|c|c|c|c|c|c|}
\hline \multirow{4}{*}{ PARÂMETROS (\%) } & \multicolumn{9}{|c|}{ Conteúdo de água de colheita (\% b.u.) } \\
\hline & \multirow[t]{3}{*}{11,7} & \multicolumn{4}{|c|}{18,7} & \multicolumn{4}{|c|}{20,6} \\
\hline & & \multicolumn{8}{|c|}{ Temperaturas do Ar de Secagem $\left({ }^{\circ} \mathrm{C}\right)$} \\
\hline & & 30 & 40 & 50 & 60 & 30 & 40 & 50 & 60 \\
\hline Tipo & 3 & 2 & 2 & 2 & 2 & 2 & 2 & 3 & 3 \\
\hline Impurezas e matérias estranhas & 0,12 & 0,25 & 0,19 & 0,29 & 0,15 & 0,12 & 0,16 & 0,17 & 0,13 \\
\hline Manchado & 0,54 & 0,60 & 0,40 & 0,51 & 0,27 & 0,49 & 0,33 & 1,07 & 1,28 \\
\hline Amassados & 0,00 & 0,04 & 0,10 & 0,12 & 0,09 & 0,19 & 0,00 & 0,20 & 0,16 \\
\hline Partidos & 5,83 & 1,93 & 1,48 & 2,36 & 1,51 & 2,63 & 2,39 & 3,00 & 2,85 \\
\hline Quebrados & 1,48 & 0,27 & 0,36 & 0,39 & 0,41 & 0,57 & 0,48 & 0,29 & 0,45 \\
\hline Picados & 0,00 & 0,00 & 0,00 & 0,00 & 0,00 & 1,28 & 0,00 & 0,00 & 0,00 \\
\hline Total de avariados & 7,99 & 5,27 & 5,19 & 6,28 & 4,84 & 7,77 & 7,36 & 8,24 & 8,87 \\
\hline Conteúdo de água & 11,7 & 11,7 & 12,0 & 11,8 & 11,6 & 11,4 & 12,1 & 11,7 & 11,5 \\
\hline
\end{tabular}


Tabela 3. Valores médios da condutividade elétrica da solução que contém os grãos de feijão colhidos com diferentes conteúdos de água e secados em diferentes temperaturas do ar de secagem, e dos grãos colhidos secados, em cada período de armazenamento

\begin{tabular}{|c|c|c|c|c|c|}
\hline \multirow{3}{*}{$\begin{array}{l}\text { Conteúdo de } \\
\text { umidade de } \\
\text { colheita } \\
\text { (\% b.u.) }\end{array}$} & \multirow{3}{*}{$\begin{array}{c}\text { Temperatura } \\
\text { de secagem } \\
\left({ }^{\circ} \mathrm{C}\right)\end{array}$} & \multirow{2}{*}{\multicolumn{4}{|c|}{$\begin{array}{l}\text { Condutividade elétrica da solução } \\
\left(\mu \mathrm{cm}^{-1} \mathrm{~g}^{-1}\right)\end{array}$}} \\
\hline & & & & & \\
\hline & & 0 & 30 & 60 & 90 \\
\hline 11,7 & & 71,25 & 73,73 & 77,86 & 84,41 \\
\hline \multirow{4}{*}{18,7} & 30 & $65,95^{\text {n.s. }}$ & $65,50^{*}$ & $74,83^{\text {n.s. }}$ & $88,13^{n . s}$ \\
\hline & 40 & $68,54^{\text {n.s. }}$ & $77,10^{\text {n.s. }}$ & $78,45^{\text {n.s. }}$ & $86,73^{\text {n.s. }}$ \\
\hline & 50 & $69,34^{\text {n.s. }}$ & $76,21^{\text {n.s. }}$ & $81,99^{\text {n.s. }}$ & $89,95^{n . s}$ \\
\hline & 60 & $74,94^{\text {n.s. }}$ & $84,79^{*}$ & $84,93^{*}$ & $92,07^{\text {n.s. }}$ \\
\hline \multirow{4}{*}{20,6} & 30 & $73,46^{\text {n.s. }}$ & $73,15^{\text {n.s. }}$ & $78,15^{\text {n.s. }}$ & $85,02^{\text {n.s. }}$ \\
\hline & 40 & $77,94^{*}$ & $86,86^{\star}$ & $84,89^{*}$ & $103,60^{*}$ \\
\hline & 50 & $78,28^{*}$ & $83,39^{*}$ & $93,21^{*}$ & $104,65^{*}$ \\
\hline & 60 & $97,95^{\star}$ & $97,58^{*}$ & $96,10^{*}$ & $108,92^{*}$ \\
\hline
\end{tabular}

* Significativo a $5 \%$ de probabilidade, pelo Teste de Dunnett

n.s. Não-significativo a $5 \%$ de probabilidade, pelo Teste de Dunnett

conteúdo de água depois de limpos, em cada período de armazenamento (Tabela 3). Verifica-se que, no início do armazenamento, ou seja, logo após a secagem, os grãos colhidos com $18,7 \%$ b.u. e secados em diferentes temperaturas do ar de secagem, não apresentaram diferenças significativas em relação aos grãos colhidos com 11,7\% b.u. Embora aos 30 e aos 60 dias de armazenamento os grãos colhidos com um conteúdo de água de 18,7\% tenham diferido significativamente em relação ao tratamento testemunha, em nível de 5\% de probabilidade, pelo teste de Dunnett, quando foram secados a temperatura de $60{ }^{\circ} \mathrm{C}$, observa-se que, aos 90 dias de armazenamento, não mais apresentaram diferença significativa porém, para os grãos colhidos com conteúdo de água de $20,6 \%$ b.u., somente os que foram secados a temperatura de $30{ }^{\circ} \mathrm{C}$, não diferiram significativamente da testemunha. Nas demais temperaturas do ar de secagem e em cada período de armazenamento, notou-se que, a medida em que se aumentou a temperatura, maior também foi a condutividade elétrica da solução que contém os grãos de feijão.

Para melhor visualizar o comportamento da condutividade elétrica $(\mathrm{CE})$ da solução que contém os grãos de feijão colhidos com conteúdos de água de 20,6 e 18,7\% b.u., secados nas temperaturas do ar de secagem, na faixa de 30 a $60{ }^{\circ} \mathrm{C}$, e armazenados no período de zero a 90 dias, ajustaram-se modelos matemáticos em função da temperatura do ar de secagem e do período de armazenamento.

Na Figura 1 encontram-se as superfícies de resposta que representam a variação da condutividade elétrica da solução que contém os grãos de feijão, em função das temperaturas do ar de secagem e dos períodos de armazenamento, para os respectivos conteúdos de água de 18,7 e 20,6\%. Observa-se que a condutividade elétrica dessa solução aumentou, sempre que se aumentaram a temperatura do ar de secagem e o período de armazenamento, cujos efeitos foram mais acentuados em grãos colhidos com conteúdo de água de 20,6\%. Resultados semelhantes foram obtidos por Afonso Júnior (1997), em estudos com sementes de feijão da variedade "Ouro Negro". De acordo com este autor, o aumento da temperatura do ar de secagem, associado ao aumento do conteúdo de água de colheita, resulta em maior condutividade

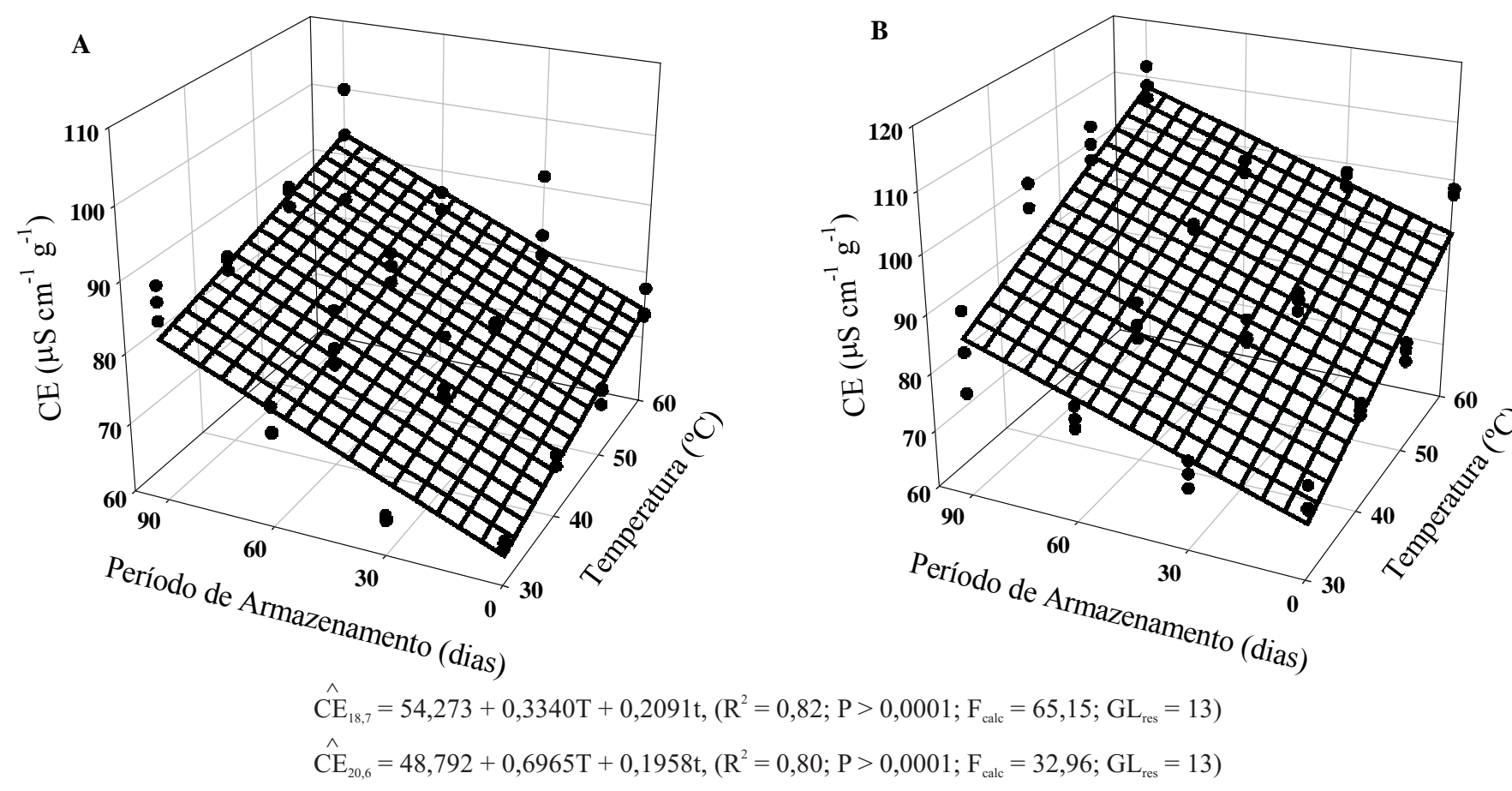

Figura 1. Superfície de resposta para predizer a condutividade elétrica da solução que contém os grãos de feijão colhidos com conteúdo de água de $18,7 \%$ (A) e $20,6 \%$ (B) b.u., em função das temperaturas do ar de secagem (T) e do período de armazenamento (t) 
elétrica da solução que contém os grãos.

Visto que o valor de condutividade elétrica da solução que contém os grãos está relacionado com a deterioração da membrana, afirma-se que, para grãos de feijão colhidos com conteúdos de água de 20,6 e 18,7\%, a melhor temperatura do ar de secagem é a de $30{ }^{\circ} \mathrm{C}$, para a obtenção de grãos com o máximo de qualidade.

\section{Coloração dos grãos de feijão}

As alterações verificadas na coloração dos grãos de feijão após a secagem e em cada período de armazenamento, foram avaliadas pelas diferenças de cor e pelos índices cromáticos. Com os valores obtidos para as coordenadas de Hunter $\mathrm{L}_{\mathrm{H}}, \mathrm{a}_{\mathrm{H}}$ e $\mathrm{b}_{\mathrm{H}}$, calcularam-se as diferenças de cor (DE) e os índices cromáticos croma $(\mathrm{C})$ e matiz $(\mathrm{H})$.

Apresentam-se, na Tabela 4, os valores médios da diferença de cor e índices cromáticos croma $(\mathrm{C})$ e matiz $(\mathrm{H})$ dos grãos de feijão colhidos com $11,7 \%$ e os grãos colhidos com 18,7 e $20,6 \%$ e secados nas temperaturas de $30,40,50$ e $60{ }^{\circ} \mathrm{C}$, em cada período de armazenamento. Constata-se que não houve variação significativa da diferença de cor dos tra- tamentos em relação à testemunha, exceto para o conteúdo de água de colheita de $20,6 \%$, quando os grãos foram secados a temperatura de $30^{\circ} \mathrm{C}$ e armazenados por 60 e 90 dias e o foram, também, a temperatura de $40{ }^{\circ} \mathrm{C}$ e armazenados durante 90 dias. Resende et al. (2004) ao monitorarem as modificações nas características tecnológicas de feijão $P h a-$ seolus vulgaris L., durante oito semanas de armazenamento em um sistema hermético, em condições controlada de temperatura e umidade relativa, $24^{\circ} \mathrm{C}$ e $87 \%$, respectivamente, na presença de equipamentos redutores de inóculo com circulação de ar forçado, verificaram que as condições de armazenamento intensificaram o escurecimento do tegumento dos grãos de feijão e, conseqüentemente, a perda de qualidade do produto ao longo do armazenamento.

Com relação aos índices cromáticos, verifica-se na Tabela 4 que, com o conteúdo de água de colheita de 18,7\%, o índice cromático $\mathrm{C}$ não diferiu significativamente da testemunha na temperatura de secagem de $30{ }^{\circ} \mathrm{C}$, nos períodos de zero e 30 dias de armazenamento. Com o conteúdo de umidade de colheita de 20,6\%, o índice cromático C diferiu significativamente, em nível de 5\% de probabilidade, pelo teste de Dunnett,

Tabela 4. Valores médios dos índices cromáticos $\mathrm{C}$ e $\mathrm{H}$ e diferença de cor (DE) para os grãos de feijão colhidos com diferentes conteúdos de água e secados em diferentes temperaturas do ar de secagem e dos grãos colhidos secados, em cada período de armazenamento

\begin{tabular}{|c|c|c|c|c|c|c|}
\hline & \multirow{2}{*}{$\begin{array}{l}\text { Conteúdo de umidade } \\
\text { (\% b.u.) }\end{array}$} & \multirow{2}{*}{ Temp. ( $\left.{ }^{\circ} \mathrm{C}\right)$} & \multicolumn{4}{|c|}{ Período de armazenamento, dias } \\
\hline & & & 0 & 30 & 60 & 90 \\
\hline \multirow{9}{*}{ C } & 11,7 & & 18,48 & 19,43 & 20,12 & 21,04 \\
\hline & \multirow{4}{*}{18,7} & 30 & $18,93^{\text {n.s. }}$ & $20,39^{\text {n.s. }}$ & $21,32^{*}$ & $22,33^{*}$ \\
\hline & & 40 & $20,08^{*}$ & $21,25^{*}$ & $21,43^{*}$ & $22,26^{*}$ \\
\hline & & 50 & $20,98^{*}$ & $21,17^{\star}$ & $21,31^{*}$ & $22,54^{*}$ \\
\hline & & 60 & $21,12^{*}$ & $21,14^{*}$ & $21,70^{*}$ & $22,50^{\star}$ \\
\hline & \multirow{4}{*}{20,6} & 30 & $19,28^{\text {n.s. }}$ & $20,18^{\text {n.s. }}$ & $20,50^{\text {n.s. }}$ & $22,07^{*}$ \\
\hline & & 40 & $18,84^{\text {n.s. }}$ & $20,36^{\text {n.s. }}$ & $20,68^{\text {n.s. }}$ & $21,77^{*}$ \\
\hline & & 50 & $20,60^{*}$ & $20,08^{n . s .}$ & $20,88^{\text {n.s. }}$ & $22,18^{*}$ \\
\hline & & 60 & $18,49^{\text {n.s. }}$ & $20,53^{\star}$ & $21,20^{*}$ & $21,97^{\star}$ \\
\hline \multirow{9}{*}{ H } & 11,7 & & 67,79 & 64,97 & 63,48 & 62,29 \\
\hline & \multirow{4}{*}{18,7} & 30 & $69,77^{*}$ & $66,71^{*}$ & $65,92^{*}$ & $63,66^{*}$ \\
\hline & & 40 & $69,45^{*}$ & $67,29^{*}$ & $65,03^{*}$ & $63,41^{*}$ \\
\hline & & 50 & $70,80^{*}$ & $68,24^{*}$ & $65,92^{*}$ & $64,67^{*}$ \\
\hline & & 60 & $70,12^{*}$ & $68,17^{*}$ & $66,36^{*}$ & $64,90^{*}$ \\
\hline & \multirow{4}{*}{20,6} & 30 & $71,27^{\star}$ & $66,90^{*}$ & $64,80^{*}$ & $62,78^{n . s}$ \\
\hline & & 40 & $69,85^{*}$ & $66,53^{*}$ & $65,45^{*}$ & $63,29^{*}$ \\
\hline & & 50 & $71,51^{*}$ & $67,39^{*}$ & $65,92^{*}$ & $65,60^{*}$ \\
\hline & & 60 & $69,55^{\star}$ & $68,20^{*}$ & $66,25^{*}$ & $64,78^{*}$ \\
\hline \multirow{9}{*}{ DE } & 11,7 & & - & 2,92 & 3,68 & 5,80 \\
\hline & \multirow{3}{*}{18,7} & 30 & - & $3,25^{\text {n.s. }}$ & $4,21^{\text {n.s. }}$ & $6,92^{\text {n.s. }}$ \\
\hline & & 40 & - & $3,35^{\text {n.s. }}$ & $3,42^{\text {n.s. }}$ & $6,16^{\text {n.s. }}$ \\
\hline & & 50 & - & $1,83^{\text {n.s. }}$ & $3,62^{\text {n.s. }}$ & $5,37^{\text {n.s. }}$ \\
\hline & \multirow{5}{*}{20,6} & 60 & - & $3,19^{\text {n.s. }}$ & $3,72^{\text {n.s. }}$ & $5,90^{\text {n.s. }}$ \\
\hline & & 30 & - & $4,05^{\text {n.s. }}$ & $5,20^{*}$ & $8,59^{*}$ \\
\hline & & 40 & - & $4,26^{\text {n.s. }}$ & $4,16^{n . s .}$ & $7,12^{*}$ \\
\hline & & 50 & - & $2,59^{\text {n.s. }}$ & $4,34^{\text {n.s. }}$ & $5,49^{\text {n.s. }}$ \\
\hline & & 60 & - & $2,84^{\text {n.s. }}$ & $4,31^{\text {n.s. }}$ & $5,87^{\text {n.s. }}$ \\
\hline
\end{tabular}

Significativo em nível de $5 \%$ de probabilidade, pelo Teste de Dunnett.;

n.s. Não-significativo. 
no tempo zero, para a temperatura de $50{ }^{\circ} \mathrm{C}$, com 30 e 60 dias na temperatura de $60^{\circ} \mathrm{C}$ e com 90 dias em todas as temperaturas do ar de secagem. Analisando-se os valores obtidos para o índice cromático $\mathrm{H}$ verifica-se, em todos os períodos de armazenamento e para os dois conteúdos de água de colheita, independentemente da temperatura do ar de secagem, que os valores diferiram significativamente, em nível de $5 \%$ de probabilidade, pelo teste de Dunnett, dos da testemunha.

\section{CONCLUSÕES}

1. A temperatura do ar de secagem não afetou a classificação por tipo dos grãos, durante o período de armazenamento.

2. O aumento da temperatura do ar de secagem diminuiu a sua qualidade fisiológica, ao longo do armazenamento.

3. O aumento da temperatura do ar de secagem, independente do conteúdo de umidade de colheita, não alterou a coloração dos grãos.

4. Independente do conteúdo de água de colheita, os grãos tenderam ao escurecimento, ao longo do armazenamento.

\section{LITERATURA CITADA}

Afonso Júnior, P. C. Efeitos imediato e latente das condições de secagem sobre a qualidade de sementes de feijão (Phaseolus vulgaris L.), variedade "Ouro Negro 1992". Viçosa: UFV, 1997. 64p. Dissertação Mestrado

Bailey, J. E. Whole grain storage. In: Sauer, D. B. Storage of cereal grains and their products. Minnesota: American Association of Cereal Chemists, 1992. 615p.
Brasil. Ministério da Agricultura. Secretaria Nacional de Abastecimento. Comissão Técnica de Normas e Padrões. Norma de identidade, qualidade, apresentação e embalagem do feijão. Portaria $\mathrm{n}^{\circ} 161$, de 24 de julho de 1987, 12p.

Brooker, D. B.; Bakker-Arkema, F. W.; Hall, C. W. Drying and storage of grains and oilseeds. New York: Van Nostrand Reinhold, 1992. 450p.

Calvo, C. Atlas de color: fundamentos e aplicaciones. Revista de Agroquímica y Tecnolología de Alimentos, Burjasot, Valencia, v.29, n.1, p.54-60, 1989.

Chiaradia, A. C. N.; Gomes, J. C. Feijão: química, nutrição e tecnologia. Viçosa: Fundação Arthur Bernardes, 1997. 180p.

CONAB. Intenção de plantio safra 2003/2004 - segundo levantamento dezembro/2003. [29/12/2003] (http://www.conab.gov.br/ download/safra/safra20032004Lev02.pdf)

Durigan, J. F.; Faleiros, R. R. S.; Lam-Sanches, A. Determinação das características tecnológicas e nutricionais de diversas variedades de feijão (Phaseolus vulgaris L.) I. Características Tecnológicas. Científica, Jaboticabal, v.6, n.2, p.215-223, 1978.

Radajewskk, E. J.; Jensen, T.; Abawi, G. Y.; Mcgahan, E. J. Drying rate and damage to navy beans. Transactions of the ASAE, St. Joseph, v.35, n.2, p.583-590, 1992.

Resende, O.; Borém, F. M.; Gris, C. F.; Pereira, R. G. F. A. Avaliação da qualidade tecnológica de grãos de feijão (Phaseolus vulgaris L.) armazenados na presença de equipamento redutor de inoculo. Revista Brasileira de Armazenamento, Viçosa, v.29, n.2, p.143-151, 2004.

Tipples, K. H. Quality and nutritional changes in stored grain. In: Jayas, D. S., White, N. D. G., Muir, W. E. Stored Grain Ecosystems, St. Paul, 1995, p.325-351.

Vieira, R. D.; Carvalho, N. M. Testes de vigor em sementes. Jaboticabal: FUNEP; UNESP, 1994. p.103-132. 